\title{
PROJETOS PARA ENVELHECER: ETNOGRAFIA DAS FORMAS DE SOCIABILIDADES E DAS TRAJETÓRIAS DE VIDA DE VETERANOS DO REMO $^{1}$
}

\author{
Luciano von der Goltz Vianna ${ }^{2}$ \\ Cornelia Eckert (orientação) ${ }^{3}$
}

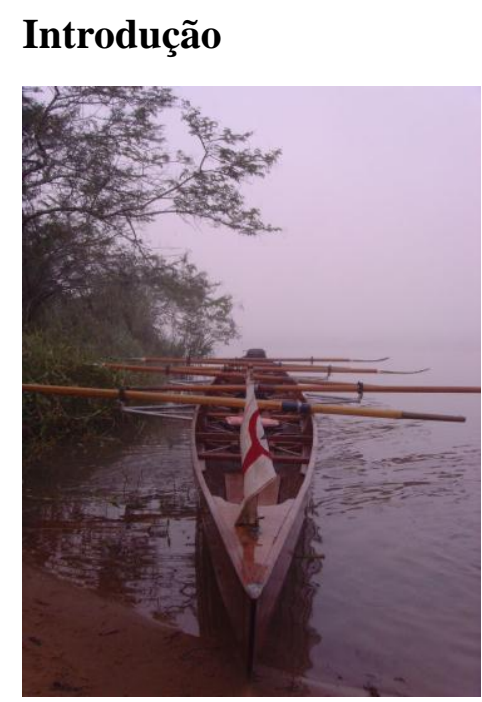

A fim de compreender as práticas de sociabilidade
a partir de Simmel (1979), objetivou-se trabalhar os
marcos teóricos da Antropologia Urbana nessa etnografia.
O grupo estudado compreende cerca de 10 senhores, entre
50 e 90 anos, que remam todas as manhãs dos domingos
em direção a uma ilha do Delta do Jacuí, Ilha do Oliveira,
pertencente ao Clube de Regatas Guaíba Porto Alegre
(G.P.A.) localizado em Porto Alegre- RS, Brasil. Buscou-
se compreender como se dão as práticas sociais e as interações dentro desse grupo. Assim como se objetivou observar como se dão as suas relações dentro de um ritual, que é o café na ilha, semanalmente realizado, onde a presença é quase exclusivamente masculina.

A pesquisa de campo desenvolvida neste clube foi iniciada em março de 2007 e finalizada em março de 2009. Durante esse período, contando com os momentos de entrevista, foram trinta e uma idas a campo.

Dentro de uma perspectiva fenomenológica, seguindo a perspectiva de Alfred Schutz, realizado no âmbito de uma Antropologia Visual e Urbana, busca-se organizar alguns conceitos em torno do tema do envelhecimento, como velhice ativa de camadas médias. Velhice essa que é projetada em formas de sociabilidade promovida pelo esporte e o lazer, assim como a participação em Associações Clubísticas.

A intenção dessa etnografia é descrever, relatar e interpretar essas formas de sociabilidade, as quais movimentam os diversos momentos e movimentos do grupo nas

\footnotetext{
${ }^{1}$ Este trabalho apresenta resultados da pesquisa "Trajetórias de uma geração de praticantes do remo e etnografia das formas de sociabilidade (POA - RS)" vinculada a realização de Trabalho de Conclusão de Curso em Ciências Sociais (UFRGS), desenvolvida sob orientação da Professora Dra. Cornelia Eckert. O presente trabalho possui consentimento para todas as imagens aqui apresentadas - captadas em trabalho de campo entre março de 2007 e novembro de 2010, exceto a foto da p. 198 que é de acervo pessoal de Damon Michalski e data da década de 30, tirada em uma ilha do delta do jacuí.

${ }^{2}$ Universidade Federal do Rio Grande do Sul, Brasil.

${ }^{3}$ Universidade Federal do Rio Grande do Sul, Brasil.
} 
manhãs dos Domingos. Para dar conta da interpretação dessas formas utilizo as obras de Georg Simmel (1979), Gilberto Velho (1981) e Alfred Schutz (1982). A perspectiva antropológica usada nessa etnografia é guiada pelas linhas da Antropologia Urbana e Visual, realizadas dentro do âmbito do Núcleo de Antropologia Visual, sob a coordenação e orientação de Cornelia Eckert.

O fenômeno presente na pesquisa está vinculado ao processo de envelhecimento da sociedade porto-alegrense nas últimas décadas. O grupo da "Guarnição dos Seis" é derivado de tradições que, no decorrer de processos históricos de imigração e colonização européia, mesclaram práticas e saberes regionais ao Estado do Rio Grande do Sul, resgatados de tradições trazidas pelos imigrantes alemães e italianos. As instituições clubísticas, entre outros contextos de sociabilidade urbana, se colocam como espaços de interação social, expressões de lazer e lugar de construção social de identidade de grupos sociais orientados por valores sociais nas sociedades ocidentais modernas. No entanto, apenas mais recentemente, no bojo do fenômeno da globalização, de uma sociedade de consumo mais autônoma e na valorização de movimentos sociais como da terceira idade que se consolida nos anos 1990, é que podemos observar idosos se organizarem em torno de grupos de trocas sociais lúdicas, sociais e políticas relacionadas aos valores como saúde, corpo, longevidade e compreendidos como conquistas emancipatórias e de direitos civis.

A metodologia empregada na pesquisa é reflexo da tradição antropológica da pesquisa etnográfica com suas ações fundantes do processo de interação e intersubjetividade entre pesquisador e sujeitos pesquisados: observação direta, escuta a partir de entrevistas e conversações e a escrita da experiência etnográfica em "diários de campo". É neles que se sintetiza a experiência vivida em campo com a experiência vivida pelo antropólogo, em reflexão e diálogo com as interpretações antropológicas. O método etnográfico realça a reciprocidade cognitiva como ponto de referência para o antropólogo em sua interação intersubjetiva com os pesquisados. Criando uma teia de significados (Geertz, 1978) tecida por ambas as partes, pesquisador e pesquisados, o antropólogo se utiliza de narrativas biográficas como fonte constitutiva principal dessa tessitura e desses deslocamentos.

"O narrador", figura trazida por Walter Benjamim, é o lugar que o antropólogo se enquadra aqui, em um deslocamento moral de seu mundo para o mundo do pesquisado. As interpretações das imagens serão, portanto interpretações do 
antropólogo. As imagens fílmicas e fotográficas produzidas na pesquisa, são analisadas e entendidas em forma de coleções conceituais orientadas por um campo conceitual.

Nessas coleções, as imagens aparecem consteladas, produzidas pelo antropólogo ou pesquisadas em acervos de imagem (Rocha, 2008) e ligadas em constelações de imagens evocadas de outras áreas, como o Cinema e a literatura, assim como da própria experiência de vida do antropólogo. As constelações de imagens são pensadas a partir do imaginário simbólico e social, assunto abordado por Gilbert Durand retomado por Ana Luiza Rocha para a pesquisa com coleções etnográficas (Rocha, 2008). Nesse sentido, o antropólogo deparase com o "problema ético-moral da coerência interna de sua produção etnográfica, que nada mais é do que o esforço da ação reflexiva do seu sujeito cognoscente diante da descontinuidade de um tempo vivido

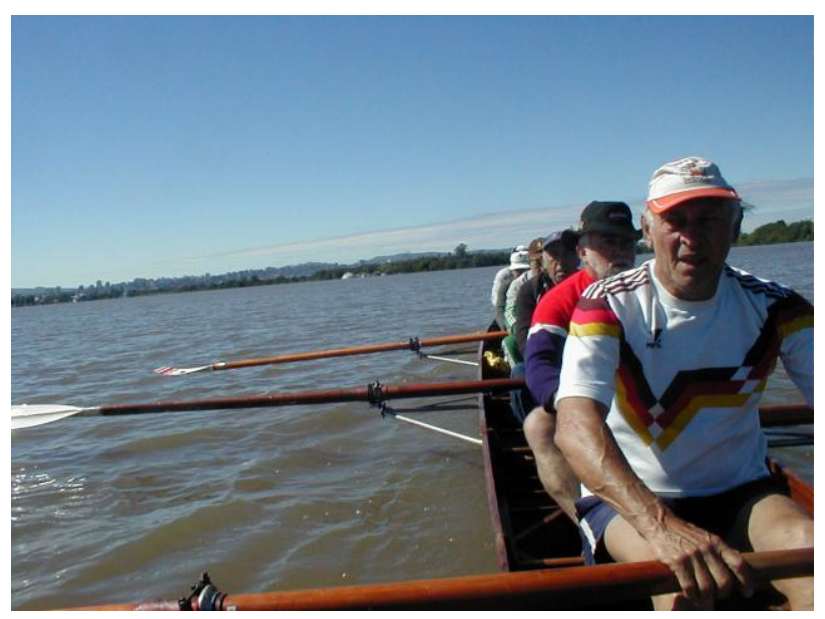
rememorado e de seu compromisso com a 'manutenção de si'" (Eckert e Rocha, 2000). ${ }^{4}$

\section{Os Seis}

Em um domingo de 10 de maio de 1936, na garagem do GPA, um grupo de veteranos do remo resolveu formar uma guarnição ${ }^{5}$ com seis remadores e um timoneiro com fins exclusivamente recreativos. Os objetivos do grupo eram continuar praticando o remo para a manutenção do vigor físico e da jovialidade de espírito através do companheirismo em íntimo contacto com a natureza. Nos primeiros anos remavam para uma ilha diferente a cada domingo.

Quando o clube, com a ajuda de alguns sócios, conseguiu comprar a ilha do Oliveira (atual ilha do GPA, pertencente ao grupo de ilhas do Delta do Jacuí) o grupo mudou seu trajeto e estabeleceu a base do café da manhã nessa ilha. A prática de fazer

\footnotetext{
${ }^{4}$ Os dois documentários etnográficos Um desafio ao tempo e Memórias de Damon Michalski publicados em http://sabi.ufrgs.br/F/YPPEMGL391S7YUKP8FMFXE5NRFUURR6N2VE1191TP6IY9RK1RX21314 ? func=full-set-set\&set number $=074238 \&$ set entry $=000002 \&$ format=999, sob direção do mesmo autor deste trabalho, são pontos de referência reflexivo imagético para a sua leitura deste artigo.

5 Tripulação de um barco movido à remo.
} 
piqueniques com cafés à moda gaúcha, ou café campeiro ${ }^{6}$ como dizem, já era uma tradição dos remadores ao final dos treinos.

O grupo atualmente é formado por senhores de idade descendentes em segunda e terceira geração de imigrantes alemães em grande maioria e italianos e portugueses em alguns casos. Em grande parte estão aposentados, o estado civil da maioria é casado, vivem em Porto Alegre, freqüentam a ilha uma vez por semana, que é aos domingos pela manhã no café na ilha e grande parte têm filhos e netos. Alguns ainda exercem suas profissões, quase todos possuem algum problema de saúde, precisando freqüentar hospitais e clínicas médicas regularmente. Deslocam-se para o clube de carro. Praticamente todos freqüentam o clube e remam desde a juventude, tornaram-se sócios do clube desde a época em que competiam.

\section{Sobre as imagens}

O momento da realização de imagens é um momento em que se definem certas questões

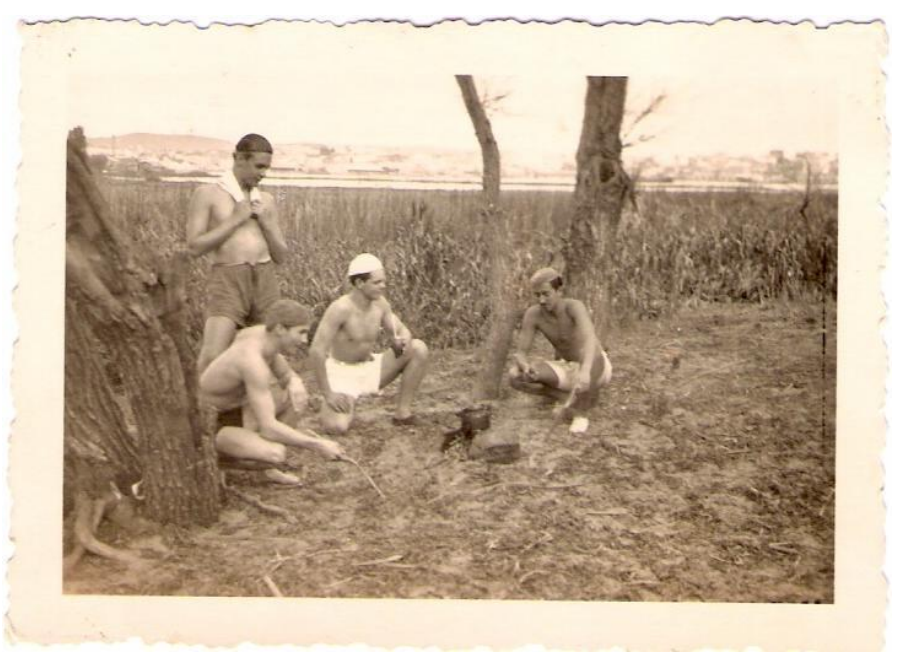
entre pesquisador e pesquisados. A imagem e sua produção são muito mais do que registros, eles são espaços sociais onde se cria uma forma diferente e sempre nova de poder ver o mundo, e a vida social. Um lugar de contestações e desconfortos, uma paisagem criada coletivamente sempre na tentativa de distanciamento do mundo real e diacrônico. Uma materialização de um tempo na qual por vezes modula (ou parece modular) a cristalização de uma memória oficial.

Essa imagem só é possível com uma imagem compartilhada, as políticas do que deve ser visto sempre estão muito claras, e o diretor/ cinegrafista deve saber que algumas imagens, mesmo que não explicitadas verbalmente, não devem ser mostradas. Muitas questões estão em jogo no momento da filmagem, desde incidência da luz, até uma palavra ou ruga proibida de ser mostrada. A imagem do outro é a imagem que o outro quer, portanto é a imagem desse outro. Os senhores do "Seis" queriam uma

\footnotetext{
${ }^{6}$ Ou também chamado de café de chaleira, no qual o processo de sua feitura consiste em "coar" o café com um pedaço de brasa em vez de filtros. Para melhor compreender o processo assistir o filme Um desafio ao tempo.
} 
imagem, se mostraram nas filmagens com essa imagem e se reconheceram, traduzindose, quando as assistiram. O papel de diretor é mais um mero olhar de espectador no que tange à honestidade deles no momento das filmagens. Todos esses aportes entram em uma divisão de categorias teóricas, empíricas e metodológicas calçadas nos principais teóricos e autores influentes nas reflexões e interpretações que dão continuidade ao trabalho de campo (Achutti, 1997; MacDougall,1997; Eckert e Rocha, 2001).

Dessa forma as imagens não são pensadas como complemento da escrita etnográfica, mas fonte, por muitas vezes principal, de dados e construções visuais empíricas do que se pensa por cada categoria antropológica trabalhada. Ao se pensar narrativas sobre o remo, como por exemplo narrativas sobre a memória do grupo ou sobre a sociabilidade masculina, dentro de uma produção de imagens, pensa-se quais imagens poderiam evocar e induzir (de forma por vezes objetiva e por outras poéticas ou metafóricas) o espectador a meandros de sua memória e imaginação. No sentido de levá-lo ao mais próximo do que se sente e se compreende quando se pensa "o que é o grupo" e o "que ele está dizendo" em toda a sua complexidade. Uma forma de dizer através de imagens, não apenas "quem são os seis", mas de levar o espectador a "viver" suas práticas e valores ao assistir as imagens. O filme final (um dos três filmes produzidos a partir dessa pesquisa) "Um Desafio ao Tempo", com seus argumentos e a linearidade das amarrações das sequiências, buscou conduzir o expectador a relativizar e se estranhar (exercício característico da antropologia). Essas amarrações são plano a plano construídas de forma que se produza esse envolvimento do espectador com as cenas e com o enredo. Foi escolhida uma estrutura visual linear, onde existe um início, um meio e um fim da história contada, na qual o ator protagonista é o próprio grupo.

\section{O ritmo da tradição do grupo}

As interações e práticas de sociabilidade estudadas no grupo são observadas e participadas em um ritual realizado todos os domingos pela manhã. O ritual rigorosamente organizado consiste em reunir sete integrantes pontualmente às 7 horas da manhã, na garagem de barcos do Clube. Os integrantes são veteranos de preferência, pois na falta de um integrante "oficial" do grupo, se substitui por algum reserva ou remador mais jovem. Mas antes ainda, na sexta feira, um integrante é responsável por ligar para todos confirmando a presença. Em grande maioria chegam de carro. Alguns se atrasam, esses recebem as severas punições: piadas durante todo o tempo de duração do café na ilha. Os que chegam vão se vestindo no vestiário do clube e ficando a postos 
para o inicio da remada. Na rampa que dá acesso ao rio, todos ficam conversando e trazendo os utensílios para o café: caixas para fazer o fogo do café, chaleiras de ferro bastante pesadas, um galão de água cheio de água potável, pães, cucas, biscoitos, leite condensado, salsicha bock, cadeiras para se sentar na ilha, algumas mudas de plantas para plantar na ilha e a respectiva pá e enxada para o plantio. Enfim essa é a "tralha”, como os sócios falam que os "Mulas", levam todos os domingos para a ilha.

A descrição do ritual do café dos seis por vezes parece ser mais a descrição de um comportamento masculino singular do que a descrição de um ritual de um grupo social ou mesmo de uma sociedade inteira. A palavra "Clube" tem aqui a conotação de reunir pessoas com interesses afins, em função da diversidade étnica e de camadas sociais e do sentimento de desolação criado pela metrópole moderna, como afirma Georg Simmel (1979) e Maffesoli (1987). Em um Clube como esse, existem regras, internas ao grupo, que definem sua inserção, modelo de comportamento esperado e atividades cotidianas exclusivas ao encontro dos integrantes do clube (como é o caso dos seis) ou fazeres rotineiros realizados fora do momento de encontro dos integrantes (como tomar uma cerveja, jogar carta ou fazer um churrasco).

Assim como outras regras, a sincronia com o ritmo do encontro do grupo também é uma característica necessária para um novo integrante participar do clube em questão. Existem temporalidades vindas da experiência vivida em comum e uma atmosfera característica do espaço e do ambiente que se constrói e se transforma no tempo, os quais para um neófito (como no caso do antropólogo em campo) devem ser percebidos, entendidos e absorvidos pelo integrante que recém chega a um grupo em uma estrutura de clube. É preciso harmonizar-se com esse ritmo, o qual é mais significante do que conhecer todas as regras de convivência e rituais que possam existir no grupo, os quais são constantemente reinventados. O que mais permanece inalterado e que mais mostra a abrangência da paisagem vivida (Simmel, 1996) pelas pessoas do grupo são as percepções apreendidas e conduzidas por um "iniciador - tutor" (no meu caso foi o senhor de apelido Bolinha que me ensinou as formas de sociabilidades na ilha, processo no qual outro integrante, Bonelli, faz analogia com o processo de um aprendiz entrando em uma firma).

O café é realizado dentro de uma atmosfera característica, dentro de um ritmo singular (assistir o filme Um desafio ao tempo). O retorno para o clube é o último

\footnotetext{
${ }^{7} \mathrm{O}$ apelido que o grupo recebeu por levar tantas coisas em um barco a remo.
} 
momento, quando todos se direcionam para "a mesa maldita". Nessa parte do ritual a atmosfera se torna diferente quebrando o rigor e a disciplina rígida.

O grande momento da manhã se segue na forma de sociabilidade já descrita, com algumas outras interações singulares, ou seja, extra- rituais. Alguns integrantes se deslocam até a praia, ou até outras partes da ilha para caminharem sozinhos. Os que vão até a beira da praia, levam pedaços de pão para dar aos peixes e os demais saem para "olhar" como está a ilha. Já outros dois, Adalírio e Nakahara (sócio de origem nipônica) costumam no verão mergulhar e nadar no rio. São práticas individuais permitidas pela dispersão ritual (Turner, 1975), onde a proposta do grupo de desopilação se transmuta do coletivo para o individual. Desopilar, se divertir isoladamente aqui é desritmar o transe coletivo para entrar em um transe individual, aqui contemplativo, reflexivo e meditativo, proporcionado pelo repouso (Bachelard, 1988), e compartilhado consigo mesmo. Esses integrantes são os veteranos mais jovens que ainda trabalham durante a semana (como o Bolinha, Adalírio, Ferreira e Bonelli) e os senhores de personalidade mais introspectiva (como o Germano). A fadiga da semana sofre o processo de desopilação através da excitação do lazer (Elias, 1992), da recondução

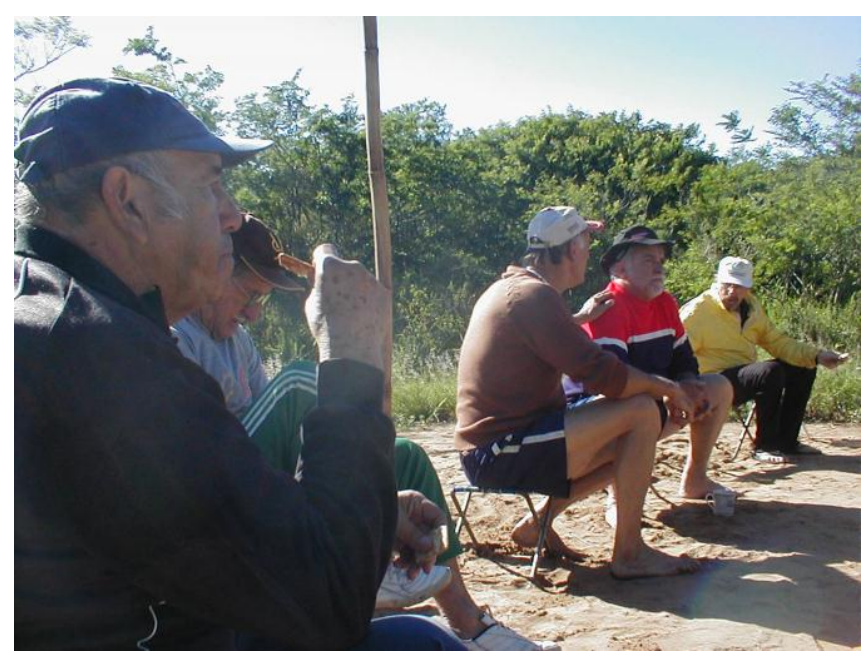
da obstrução nervosa causada pelo estresse cotidiano da vida na cidade (Dias Duarte, 1986). Os demais senhores também sofrem a mesma obstrução nervosa da vida diária, no entanto estão há alguns anos em uma nova fase da vida, a qual é a aposentadoria. Esses últimos, conduziram suas atividades para práticas em forma de hobbie ou lazeres que no dia- a - dia preenchem suas rotinas (atividades essas que dei profundidade em entrevistas individuais). Se busca a desopilação através de atividades contemplativas das paisagens e sensações que remetem à outras esferas da vida cotidiana que não estejam vinculados aos problemas e estresses, e sim aos prazeres da vida diária. Também buscam essa desopilação nas memórias que o espaço presente, a ilha, remete a experiências passadas. É por essas razões que o restante do grupo aceita que alguns membros necessitem se isolar por alguns momentos para terem suas experiências nesse espaço de forma isolada. 
As conversas seguem com vivacidade e empolgação por parte de todos nas pequenas rodas, ou em alguns momentos, quando se tem algum grande narrador (Bonelli) ou veterano respeitado (Germano) falando todos cessam de falar para dar voz somente à aquele veterano.

O ritmo transcorre assim até que alguém tenha olhado as horas ou alguém respeitado como Germano, Lederes ou Wily ou ainda alguém ranzinza (Lederes ou Bolinha) grita para todos que está na hora de se mexer. Existem também situações nas quais algum integrante precisa sair mais cedo como o Ferreira, o Copetti ou Juarez.

\section{O que é ser velho}

Partindo de dois temas centrais da pesquisa, masculinidade e envelhecimento, penso as representações do que é ser um homem velho, (no caso da pesquisa caberia melhor o termo êmico "senhor de idade") na cidade de Porto Alegre durante o século $\mathrm{XX}$, no sentido do que é ser velho atualmente para os integrantes do grupo. Os estudos de corpo, performance, corporalidade, masculinidade, doença e sexualidade são imprescindíveis para a interpretação dessas representações, através de uma etnografia visual. A incorporação de certas identidades é evidenciada através de narrativas (que já evocam imagens sobre si no passado e na cidade) mas antes através de uma imagem de si, corporificada na interação etnográfica. Durante essa interação a realização de fotos e vídeos transforma-se na potencialização do ethos masculino evocado durante a experiência etnográfica, através da perfomance dos "atores ilhéus". Portanto o desafio é observar aqui como se dão as diversas possibilidades de construção e reconstrução da continuidade desse corpo velho, na duração desse tempo a que chamamos velhice. $\mathrm{O}$ grupo se articula constantemente na direção de alicerçar as experiências de terem vivido um tempo em comum passado, mas muito além disso, estarem vivendo um tempo presente juntos "resistindo ao tempo".

\section{Envelhecendo e amadurecendo}

O desconforto de etnografar com indivíduos velhos, idosos ou anciões pertencentes ao que se chama de terceira idade, significa trabalhar, mais cedo ou mais tarde com a perda. A disparidade que existe entre a experiência de vida de um jovem e um veterano está no exercício de alteridade, no sentido de trabalhar com "projetos" e trajetórias de vida (Velho, 2003). Na qual na primeira situação o indivíduo está se construindo como tal dentro de um projeto, e a outra está finalizando a sua trajetória. A 
disparidade aqui está em viver as impossibilidades corporais, viver as perdas, viver o desapego, a discriminação, o descaso, a rejeição, o esquecimento, a depressão, a perda gradativa e degenerativa das capacidades físicas, psicológicas e sexuais. A disparidade é viver com a presença constante da morte. Observação participante requer uma abordagem íntima desse outro. A produção de uma certa confusão entre valores, práticas, vivências e saberes do outro e do antropólogo é claro depois de algum nível de intimidade com os interlocutores.

O brio pela vida está presente na vida de quase todos os integrantes dos seis, eles compartilham entre si, através de memórias presentes e sonhos futuros, uma alegria de viver em comum decorrente de um estilo de vida comum onde o esporte é o ponto de convergência para o motivo principal dessa alegria de viver. Mas muito mais do que isso é alegria de estarem juntos, de ser "um dos", de conviver em um lugar em comum e compartilhar esse momento e esse lugar da vida a que chamam envelhecer. E é nesse lugar (espaço, ilha) e com esse estilo de vida que os olhares sobre um conjunto de "sentidos da vida" (exercício característico do processo de construção de projetos de

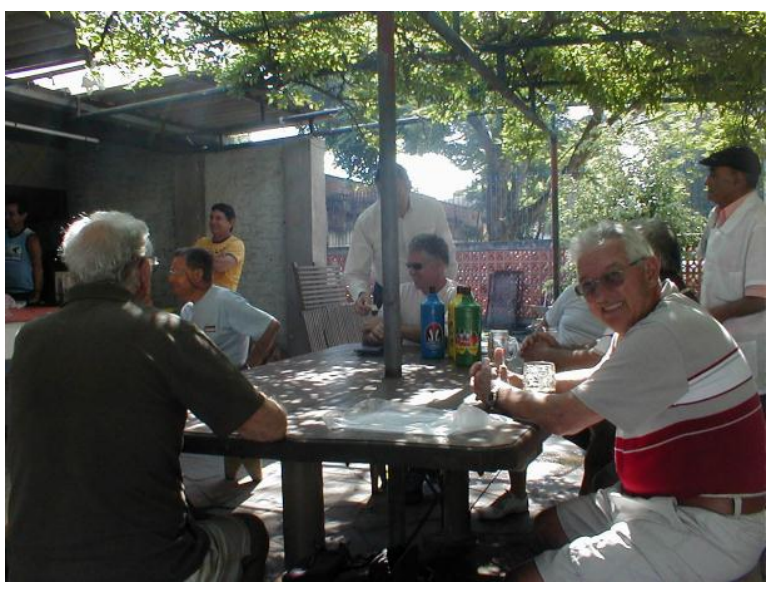
vida pelo indivíduo) é apreciado e contemplado entre antropólogo e senhores dos seis. Os objetivos das imagens produzidas foram ao encontro desses sentidos, buscando um olhar sobre esse ponto de vista sobre a vida.

A questão "vida" aqui presente é constantemente retomada por um motivo óbvio: envelhecer é o momento de finalizar a vida, de concluir tudo o que foi feito e realizar algo que permaneça no tempo. A imagem aqui para eles é vista como uma possibilidade a mais dessa realização. Um ensinamento quer ser passado acima de qualquer outro saber e fazer. Os "Seis" querem ensinar a viver, e no momento certo (da forma certa), a morrer. Quem "não sabe morrer" é censurado pelos outros, assim como quem quer morrer sozinho. A vida e sua beleza são exaltadas por que existe uma compreensão geral do que se entende de vida e sua forma de vivê-la, a idéia de ser um veterano é a idéia que se passa de ser no clube alguém que já "passou por tudo" e pode dizer como se deve passar por tudo. As pessoas mais jovens que vão à ilha não vão com um olhar de assessoria, assistência ou piedade da velhice e do fim da vida, mas sim são tratados como "os anciões sábios", os que 
podem dizer como a vida é; um "oráculo" onde se podem encontrar respostas para as grandes questões e dúvidas da vida social e pessoal.

Os exercícios etnográficos graduais foram os de refletir sobre o processo de envelhecer, de envelhecer e de se sentir velho, de conviver com eles e envelhecer junto, de conhecer um modo de se envelhecer na cidade. Mas o exercício etnográfico constante de deslocamentos morais e aproximações ao "mundo da vida" dos interlocutores da experiência etnográfica (exercício o qual transforma o antropólogo em um laboratório psicanalítico de emoções, sensações e perspectivas de mundo) pode acarretar em consequiências nada confortáveis para quem desenvolve etnografia levando em conta a relação intersubjetiva. Assim como pode acarretar a visualização de que as duas esferas e visões de mundo se transformam em uma só experiência de vida, e que questões como as que são levantadas no presente trabalho, não poderão ser objetivadas racionalmente em métodos rigorosos científicos apenas.

\section{Sociabilidades e/com os corpos}

Os domingos pela manhã ainda trazem uma reconstrução ou uma manutenção desse corpo velho, que com a prática do remo, definem a virtude e a honra de um homem. Pois o remo, de acordo com as narrativas deles, é o esporte mais aconselhado pelos médicos a se praticar por todas as idades. É o exercício que contempla todas as partes do corpo e que define e solidificam valores e práticas do cotidiano através da disciplina da técnica do remo, da obediência as normas da harmonia do grupo da remada e ao timoneiro, o qual estabelece essa ordem através de certos comandos e do rigor de comportamento.

A proposta apresentada pelo grupo é de ser um grupo de senhores, uma guarnição de remadores independentes do clube e de qualquer ajuda externa, tendo assim regras próprias que definem não somente um estilo de remada própria, explicada adiante por um dos informantes, o Bolinha, como "a filosofia do seis"; assim como regras de comportamento próprias, uma moralidade construída em cima do que o Bolinha exemplifica como "desopilação".

Como na fala da entrevista gravada em vídeo, a voz do Bolinha vem resumindo o grupo nas seguintes palavras: ...os seis é isso: é mais brincadeira e lazer, agente vem aqui pra desopilar e não assimila mais problema, já basta os que agente tem no dia dia.

O momento da cerveja na mesa maldita seria o de diversão mais declarada mostrada no filme, não sendo necessariamente o momento de maior prazer na manhã, 
mas um momento que sobreposto a fala dele, dá sentido ao que levou a interpretação mantida nesse artigo até agora a formular em imagens, ou seja o que é desopilação e lazer: estar entre amigos desfrutando dos prazeres, dramas e experiências em comum de suas vidas.

A motivação para as provocações vem do sentimento de desopilação e do apego uns pelos outros. Partindo do fato de existir uma comunhão de saberes entre as diversas personalidades, as características das nuances, das mais diversas identidades ali presentes, podem ser realçadas com motivos de gozação ou de orgulho, para estabelecer os vínculos de proximidades e afastamentos. Através da jocosidade ou da reificação de cada personalidade se abre a possibilidade para refletir constantemente a sua própria posição no mundo. É através dessa forma de sociabilidade que o diálogo se elabora grupalmente. As trocas de experiências são recriadas por cada narrador e arranjadas em quadros sociais da memória (Halbwachs, 1990) a partir da narração do último contador de um "causo" da conversa em questão, ou de outras lembranças que o assunto em questão da narrativa tenha lhe evocado. O que se fala depende do que se lembra, e como se lembra depende de que forma se pode contar o que se lembra. O ditado popular recorrente em nossa sociedade "quando um burro fala o outro abaixa as orelhas" é uma norma de convivência implícita entre o grupo, a qual depende da performance do narrador. Se determinado senhor não consegue chamar atenção suficiente de todos com seu enunciado da fala, ou quer trocar radicalmente o assunto da conversa (assunto o qual não teria relação nenhuma com o assunto anterior) sem argumentar o porquê de estar lançando um assunto novo, então ele não será ouvido, sendo possivelmente interrompido por algum outro narrador que esperava "na fila" para falar. Para compreender o que se fala sobre rejuvenescimento na ilha, é preciso destacar quais são os elementos simbólicos sintetizadores das reflexões derivadas do ritmo da experiência na ilha e da sensação de repouso ao sentar em roda e conversar coletivamente ou intimamente com um interlocutor.

A prática não define a cultura em um viés unilateral, a cultura elabora e reelabora constantemente as práticas, re-significando-as (Sahlins, 2003). Entre a cultura e a prática está um veículo permanente do deslocamento entre as duas: a motivação, a excitação do lazer (Elias, 1992) ou a "desopilação". Os estados mentais possibilitam a imagem de situações vividas e rearticuladas através do diálogo entre vivências afins, conduzindo coletivamente o grupo a outras temporalidades e espacialidades vividas e apreendidas concomitantemente. 


\section{Conclusões}

De acordo com o antropólogo Gilberto Velho os indivíduos constroem projetos em suas vidas, com influências de suas respectivas regiões morais (Park, 1979). Mas o grupo da Guarnição do Júpiter, me apresentou proposta outra que o acumulo de projetos individuais em comum que se cruzaram por motivos aleatórios ou por esforços individuais de reagrupamento por afinidades em comum. A proposta do Seis, de acordo com a presente interpretação desse artigo, é de envelhecer em conjunto, compartilhando as experiências desse processo as quais estão dentro de um projeto coletivo de envelhecimento do grupo. Se na velhice o futuro pensado é um futuro de poucos projetos de vida, ou nenhum até; se a etapa da vida do repouso, afim da reflexão aprofundada sobre os próprios motivos da vida, não se torna em nossa sociedade uma instituição qualquer da sociedade assim como nas demais etapas da vida, então os próprios indivíduos vão criando futuros outros, projetos outros, com referências outras que não de sua contemporaneidade e sim de outros tempos não vividos, mas relatados, apreendidos, interpretados e revividos.

A busca do grupo não é imitar e resignificar práticas e saberes (de Certau, 1988) de outros tempos dos antigos remadores, dos seus antepassados ou ainda das origens de suas etnias. Existe uma proposta para quem está disposto a renovar suas considerações sobre a morte e sobre o envelhecimento, numa tentativa de luta contra o tempo, uma proposta de desafiar o tempo e se preparar para o percurso incontingente inevitável que será a morte. Entrar para o Seis é um segundo rito de passagem para a velhice, onde a aposentadoria é o primeiro.

As questões acabaram me guiando para o que se denomina no senso comum, metafísico e filosófico de "o sentido da vida". Pois qual seria o sentido mais claro perante o fim da vida senão a sua avaliação distanciada após um fim simbólico da vida? As questões colocadas nos discursos, narrativas e conversas entre "os seis", circulam entre como cada um viveu durante sua trajetória de vida (trocas de práticas e saberes) e como se pode chegar até o fim da vida e encará-la? O drama social aqui, portanto, é viver a perda, a perda da vida, dos parentes e amigos próximos e a principalmente, a perda da juventude (etapa da vida na qual se tem as referencias de apogeu social, físico e sexual em sociedades ocidentais). Para isso fui tecendo uma "teia de significados" (Geertz, 1978) que dessem conta desses temas. Envelhecendo junto com os "Seis". Amadurecendo, me desafiando a viver a minha "nova velhice" na juventude e a juventude na minha futura velhice. Viver de forma intensa as perdas, viver o 
esquecimento, o isolamento, as faltas gradativas de capacidades físicas, as marcas da experiência gravadas na memória do e no corpo e de forma mais enfática e significativa,viver a duração do tempo vivido. Por vezes, vivendo a euforia da vida dinâmica, fluída e líquida que é a vida de um jovem na cidade, e por vezes vivendo o tempo lento, "despreocupado", fixo constantemente em pontos do passado, em quadros imagéticos da memória, em quadros sociais da memória (Halbwachs, 1990) e por muitas vezes viver com desgosto o tempo presente, por não ser mais como "antes", com poucas perspectivas de melhorias para o futuro. Vivência essa caracterizada aqui um ethos "ranzinza" definido pelo grupo do "Seis", presente constantemente nos comportamentos e falas de todos os integrantes. Vivendo todas essas sensações, sofrendo todos os constrangimentos que implicam envelhecer para qualquer pessoa em qualquer idade pude compreender, relatar e "maginar" nas imagens aqui apresentadas, o processo vivido de forma constante em nossas vidas a que chamamos amadurecimento. Fruto dessa etnografia e exercício buscado nela e nas imagens produzidas, as quais são em grande parte pontos de partida para as reflexões nessa etnografia visual e urbana sobre as formas de sociabilidade e as formas de se envelhecer.

\section{Referências}

ACHUTTI, Luiz Eduardo. Fotoetnografia. Porto Alegre: Tomo Editorial, 1997. BACHELARD, Gaston. A Dialética da Duração. São Paulo: Ática, 1988.

BARROS, Myriam Moraes Lins. "Testemunho de vida: um estudo antropológico de mulheres na velhice". In: Perspectivas Antropológicas da mulher 2. Rio de Janeiro: Zahar, 1981.

BENJAMIN, Walter. "O narrador. Considerações sobre a obra de Nikolai Leskov". In: Magia e técnica, arte e política. Ensaios sobre Literatura e Historia da Cultura. São Paulo: Brasiliense, 1993. p. 197 a 221.

BOSI, Ecléa. Memória e sociedade. Lembrança de velhos. São Paulo: Queiroz ED. Ltda, e EDUSP, 1987.

CERTAU, Michel de. A Invenção do Cotidiano. Artes de fazer. Rio de Janeiro: Vozes, 1988.

CORBIN, Alain. O território do vazio. A praia e o imaginário ocidental. São Paulo: Companhia das Letras, 1989.

DA MATTA, Roberto. A casa e a rua. São Paulo: Brasiliense, 1985.

DEBERT, Guita. "Envelhecimento e representação da velhice". In: Revista Ciência Hoje, vol 8, $n^{\circ} 44$, junho de 1988.

DIAS DUARTE, Luiz Fernando. Da vida nervosa, nas classes trabalhadoras urbanas. Rio de Janeiro: J. Zahar Ed./ CNPq, 1986.

DUMONT, Louis. $O$ individualismo: uma perspectiva antropológica da ideologia moderna. Rio de Janeiro: Rocco, 1985.

DURAND, Gilbert. A imaginação simbólica. São Paulo: Cultrix, 1988. 
ECKERT, Cornelia e ROCHA, Ana Luiza Carvalho da. "Filmes "de" memórias: do ato reflexivo ao gesto criador". In: Revista Cadernos de Antropologia e Imagem, n.10. Rio de Janeiro: UERJ, NAI, 2001.

ECKERT, Cornelia e ROCHA, Ana Luiza Carvalho da. "Imagens do tempo nos meandros da memória: por uma etnografia da duração". In: KOURY, Mauro GP. (org.) Imagem e memória: Estudos em Antropologia Visual. Rio de Janeiro: Garamond, 2000. ELIAS, Norbert. A busca da excitação. Lisboa: Difel, 1992.

ELIAS, Norbert. A Sociedade dos Indivíduos. Rio de Janeiro: Zahar, 1994.

ELIAS, Norbert. Os estabelecidos e os Outsiders. Rio de Janeiro: Jorge Zahar Editor, 2001.

GEERTZ, Clifford. A interpretação das Culturas. Rio de Janeiro: Zahar, 1978.

GOFFMAN, Erving. A representação do Eu na Vida Cotidiana. Petrópolis: Vozes, 2008.

GRAEFF, Lucas. "Os Tempos no Asilo: uma reflexão sobre uma experiência de estágio em Psicologia Social”. In: Estudos Interdisciplinares sobre o Envelhecimento, v.5. Porto Alegre: UFRGS, 2004.

HALBWACHS, Maurice. A memória Coletiva. São Paulo: Vértice, 1990.

MACDOUGALL, David. "De quem é essa estória?". In: Cadernos de Antropologia e Imagem, v. 5, n. 2. Rio de Janeiro: UERJ, 1997.

PARK, Robert E. "A cidade: sugestões para a investigação do comportamento humano no meio urbano". In: VELHO, O.G.(org.), O fenômeno urbano. Rio de Janeiro: Zahar, 1979.

ROCHA, Ana Luiza Carvalho da. "Coleções etnográficas, método de convergência e etnografia da duração: um espaço de problemas". In: Revista Iluminuras, v. 9, n. 21. Porto Alegre: BIEV/ UFRGS, 2008.

SAHLINS, Michel. Cultura e razão prática. Rio de Janeiro: Zahar, 2003.

SCHUTZ, Alfred. A fenomenologia e as relações sociais. Rio de Janeiro: Zahar, 1982.

SIMMEL, Georg. "A filosofia da paisagem”. In: Revista Politica e Trabalho. Paraíba: PPGS/UFPB, 1996.

SIMMEL, Georg. "A metrópole e a vida mental”. In: VELHO, O.(org.) O Fenômeno Urbano. Rio de Janeiro: Zahar, 1979.

TURNER, Victor. O Processo Ritual. Petrópolis: Vozes, 1974.

VELHO, Gilberto. Individualismo e Cultura: Notas para uma Antropologia da Sociedade Contemporânea. Rio de Janeiro: Zahar, 1981.

VELHO, Gilberto. Projeto e metamorfose, Antropologia das sociedades complexas. Rio de Janeiro: Jorge Zahar, 2003.

Recebido em: 17/12/2010

Aprovado em: 25/03/2011 